\title{
Winning the War for Talent: An Experimental Evaluation of Online Recruitment Campaigns Using Twitter
}

\author{
Margarita Torre ${ }^{1} \&$ Alejandro Llorente ${ }^{2}$ \\ ${ }^{1}$ Department of Social Sciences, Universidad Carlos III de Madrid, Getafe Campus, 28903, Madrid, Spain \\ ${ }^{2}$ PiperLab, Madrid, Spain \\ Correspondence: Margarita Torre, Department of Social Sciences, Universidad Carlos III de Madrid, Getafe Campus, \\ 28903, Madrid, Spain.
}

Received: December 27, 2018

Accepted: January 15, 2019

Online Published: February 11, 2019

doi:10.11114/bms.v5i1.4049

URL: https://doi.org/10.11114/bms.v5i1.4049

\begin{abstract}
Organizations have moved rapidly from traditional recruitment methods to online recruiting. The present study argues that the fierce demand for labor in technology-related industries - "second war for talent"- besieges workers in competitive environments to the point of lowering their propensity to engage in online recruiting campaigns. Collecting data from the social media platform Twitter, we take an experimental approach to investigate the effectiveness of online recruitment processes in attracting the attention of potential job candidates from different occupational categories. The findings reveal that workers in technology, engineering, and mathematical occupations (TEM) are less likely to react to recruitment processes than workers in other professional jobs. However, motivated advertisement designed according to individual group interests significantly increase the rate of participation of TEM, while these ads have no effect on workers from other sectors. Our experiment helps to explain pre-hiring outcomes. The findings have important implications for organizations seeking to boost their talent acquisition strategies.
\end{abstract}

Keywords: online recruitment, talent, Twitter, influencers, experiment

\section{Introduction}

Technological advances have provoked striking changes in the recruitment strategies employed by organizations (Cappelli, 2001). Early on, savvy recruiting and professionals from the Human Resources field recognized social networks (e.g., LinkedIn, Facebook, and Twitter) as a gold mine of passive candidates (Allen et al., 2007). Now, they are even building out entire, multi-pronged recruitment campaigns that take advantage of social media's high engagement rates as well as the convenience, flexibility, and ease of mobile platforms (Vorhauser-Smith, 2013).

The recruiting literature argues that being successful when attracting applicants is crucial for organizational effectiveness (Laumer, et al. 2010; Capelli, 2008; Spector 2000). Previous studies have widely examined the types of technologies and strategies used in online recruitment and selection (Baum and Kabst, 2014; Chapman and Webster, 2003; Caers and Castelyns, 2011; Braddy et al, 2003; Zusman and Landis, 2002), but they fall far short of providing a full assessment of how pre-hiring outcomes vary across types of potential employees. Are all workers equally reachable on the Internet? How do potential employees in different occupational categories respond to online recruitment campaigns? Beyond salary and job conditions, what might make a candidate be interested in an offer and click on an online advertisement? This article contributes to fill this gap by analyzing the effectiveness of online recruitment campaigns in attracting the attention of potential job candidates from different occupational categories. The expansion in technology and the recovery from the global economic recession have fueled a demand in TEM occupations (technology, engineering, and mathematics), to the point that labor professionals speak of a "second war for talent," a renewed peak in demand following the surge in technology in the closing years of the twentieth century (HR, 2015; Mandhanya and Shah, 2010); Beechler and Woodward, 2009). This study contends that because of this fierce demand for labor in technology-related industries, TEM workers react differently to online campaigns than those in other non-TEM professions (such as physical, social sciences, and other sectors).

Collecting data from the social media platform Twitter, this investigation takes an experimental approach to investigate the relationship between online procurement advertising and an individual's position in the labor market. First, information from users' biographies (short self-introduction written by users in free from) is extracted to determine their 
occupations and classify them into occupational categories (TEM vs. non-TEM) (Ding and Jiang, 2014). Second, the influencers of each group are identified: famous business or cultural figures who are especially popular or trusted by group members. Third, a split test is design to measure users' reactions to group-tailored talent-procurement ads. The test has different focuses. Some focus on the brand, others on the core corporate message, while a third takes a motivated approach and uses quotations (inspirational, aphoristic, etc.) from the taste-making influencers. Finally, web-based campaigns are launched to controlled target groups, which allows us to compare the campaigns metrics (click through rate and engagement rate) of three types of advertisements. The findings reveal that potential employees in high demand (TEM) are less likely to react to online campaigns than potential employees in other professional occupations. However, motivated ads, which are tailored to individual group interests, did significantly increase the rate of participation among the first group, while no effect is observed among the rest of the workers. Consequently, incurring the costs of customization is worthwhile when seeking to attract workers in high demand.

Overall, our experiment uncovers the crucial distinctions among worker types that help explain pre-hiring outcomes and should inform recruitment practices. The increasing divide between those TEM workers most prized in the war for talent and others poses new challenges for companies in their personnel recruitment (Gardner, 2001; Cappelli, 2001). Thus, the findings have important implications for organizations seeking to boost their talent strategies. The present study focuses on the Spanish territory, since our experiment would not make sense if it included people living outside of the country. However, results can be extrapolated to any context in which there are divergent levels of demand for worker populations.

\section{Literature}

The web has revolutionized the relationship between organizations and people in many ways. Firms have increased online advertising efforts (Interactive Advertising Bureau 2013), web-based research techniques have impressively expanded the ability to online recruiting participants (Shatz, 2017), and community-based and non-profit organizations have sought to enhance organization services (Al-Ammary and Hamad, 2012; Deninson and Williamson, 2012). The Human Resource Management sector has also moved in this digital direction, transitioning rapidly from traditional recruitment methods (newspaper advertisements, etc.) to online recruiting (Dinnen et al., 2007; Chapman and Webster, 2003). The payoffs of Internet recruiting can be enormous in terms of saved time and money (Kay, 2000; Cappelli, 2001), but such a strategy also provides the opportunity to reach the best employees, regardless of their geographical setting (Chapman and Webster, 2003). Given the benefits of internet recruiting in reducing expenses and enhancing efficiency, it has increasingly gained prominence over traditional recruiting methods.

The online hiring process can be divided into three steps: attracting, sorting, and contacting candidates. In the first, an employer brings a job opening to the attention of potential job candidates who do not currently work for the organization; this is key to procuring the best candidates (Spector, 2000). The rise of social networks has facilitated this process enormously by making it easier to reach a wide range of people and providing information about users' personal interests (McDonald et al., 2016; Walrave et al., 2016; Morris, 2013;). As argued by Boyd and Marwick (2011), information used to be private by default and public through effort. Nowadays, social media often reverses this alignment: information is public by default, private only through effort. Indeed, recent analyses of personal posts on Twitter found that overwhelmingly, tweets were about (and thus provided information about) people, and most often (around 65\%) about the Twitter writers themselves (Humpreys, 2014). Users rarely share sensitive personal information, but they do often provide information about what they do, when they do it, and where they are (Humphreys, 2014). Metadata extracted from social networks allow companies and researchers to study a user's mobility (Jurdak, 2015), temporal patterns (Yang, 2011), creation and termination of friendships (Kirvan-Swaine, 2011), modeling economic indicators such as unemployment rate (Llorente et al., 2015), and other general behavioral patterns ( $\mathrm{Li}, 2013)$. Companies collect this information and use it to customize advertisements in two ways. First, they personalize the message by including references to the consumer's identity in the message content. Second, they tailor the message to match the receiver's preferences (Walrave et al., 2016; Maslowska, 2013).

Both personalization and tailoring have been shown to have positive effects on brand and campaigns responses (Kim and Sundar, 2012; $\mathrm{Xu}$, Liao, and $\mathrm{Li}, 2008$ ), as consumers are motivated to engage more with relevant messages (Allen et al., 2007; Allen et al., 2004). However, recent research has raised caveats about the potential adverse impacts and privacy issues involved with such persuasion strategies (van Doorn and Hoeskstra, 2013; Seetonce et al., 2005; Friestad and Wright, 1994), demonstrating the trade-off between the positive effects of tailoring and the increased intrusiveness involved. ${ }^{1}$

\footnotetext{
${ }^{1}$ Walrave and his colleagues (2016) examined how adolescents respond to motivated ads. The study found a strong positive relationship between personalization and positive responses among the young people. Also, they found no evidence of privacy concerns among this group.
} 


\section{Online Recruitment in the Second War for Talent: The Increasing Divide Among TEM and Non-TEM Workers}

Scholars have increasingly turned their attention to online recruitment strategies (Breaugh, 2008; Boswell et al., 2003; Dineen et al., 2007; Braddy et al., 2003). Despite the wide-ranging research, though, the literature has thus far has failed to address how the persuasion process varies according to the targeted worker. Do all workers respond similarly to online campaigns? How important are inducements for workers in different types of occupations? In this paper, we argue that people in different occupational categories might display varying propensities to interact with online recruitment efforts.

In 1998 McKinsey \& Company coined the expression the "War for talent," which referred to the difficulties that companies experienced in hiring, and retaining, certain highly valued employees toward the end of the twentieth century (Michaels et al., 2001). During this period, companies offered high bonuses when hiring; in turn, the employees, aware of their advantage, demanded frequent wage increases, sometimes just several months after starting their jobs. At the same time, recruiters were chasing the best candidates, offering them better pay and thus further increasing competition. Almost twenty years later, history is beginning to repeat itself. The recovery from the global economic recession, along with the increasing demand for technical skills in the labor market, have once again intensified the head-to-head competition among employers over high-skilled workers. This state of affairs has given rise to a second war for talent. Indeed, as highlighted by the Human Resources Global Barometer (2015), the technology sector identifies two hiring-related priorities significantly and more frequently than other sectors: talent recruitment ( 45 percent, compared to 32 percent overall) and employee retention ( 36 percent, compared to 26 percent overall). Moreover, while 26 percent of companies across all industries expect to increase their total workforce within the next twelve months, that figure rises to 40 percent among technology companies. Because of the fierce demand for labor in technology-related industries, 44 percent of technology organizations report spending over 10 percent of their human resources budget on recruitment. Across all industries, only 31 percent hit that spending level (Human Resources Global Barometer, 2015).

The war for talent has now moved to the Internet. As pointed out before, the Internet has significantly decreased the time and money costs of recruiting (Cappelli, 2011). Moreover, online recruitment practices afford companies the opportunity to contact both active and passive candidates (i.e., highly valued candidates employed in other companies who might consider changing occupations in case they receive a better offer) from all over the world (Chapman and Webster, 2003). However, this increasing scope might have undesired side effects. A potential drawback of corporate websites and broadbased recruitment sites is that they generate too many applications from unqualified applicants (Dineen et al., 2007; Sonnet et al., 2005). Similarly, workers are often inundated with notifications and job advertisements that are not relevant to them. Because of this besiegement, workers might simply choose to ignore online recruitment ads.

Here, we contend that technology and related industries on the front line of the second war for talent are particularly likely to suffer these side effects of the online recruitment age. Paradoxically, their privileged situation in the labor market might be causing fatigue among these workers, who often receive offers for which they are overqualified or do not suit them. Consequently, we expect workers in these sectors are less susceptible and responsive to online outreach than other workers. Concretely:

$\mathrm{H}_{1}$ - TEM workers show lower levels of interaction with online persuasion attempts than workers in other occupations.

Because of TEM workers' reluctance to engage with online advertising, companies must make extra efforts to catch their attention. In other words, companies looking for workers in high-demand will have to invest more resources in increasing desirability and credibility of the ad. A way to do this is to add more information and customize recruitment campaigns, which according to prior research would resulted in the job opening being viewed as more convincing and trustworthy (Allen et al., 2007, Allen et al., 2004). Therefore, we hypothesize the following:

$\mathrm{H}_{2}$ - The recruitment benefits of customization are higher for TEM workers than for workers in other sectors.

\section{Data and Methodology}

To perform our analysis, we consider 0.6 million Twitter accounts ${ }^{2}$ collected through the public Rest APIs provided by Twitter $^{3}$. The original sample is processed as follows. First, we delete duplicate records. Second, we restrict the sample

\footnotetext{
2 This figure is easily expandable. We'll decide after cleaning and validating the data whether the sample is representative or if it is necessary to increase it.

${ }^{3}$ Specifically, we first call the GET followers/ids endpoint to collect user IDs of individuals following certain accounts. We consider a wide variety of accounts (both topic-related and of general interest) to maximize heterogeneity. Then, we use the list of IDs returned to call the GET users/lookup, which provides fully hydrated user objects. It is important to note that GET users/search endpoint allows for querying by topical interest, full name, company name, location, or other criteria. However, exact match searches are not supported, and only the first 1,000 matching results are available. These two constraints prevent us from using this endpoint. For more information on REST API endpoints and users, see https://dev.twitter.com/rest/public and https://dev.twitter.com/overview/api/users.
} 
to individuals residing within the Spanish territory (regardless of their nationality), since our experiment would not make sense if it included people living outside of the country. A straightforward way to accomplish this would be to use geolocation based on the user's IP address. However, this information is only available with individuals who voluntarily activate this option. According to prior studies, less than 2 percent of Twitter accounts are associated with a geolocation (Leetaru et al., 2013; Jurgens et al., 2015). Given this limitation, we extract information from the "location" field to determine people's whereabouts. Concretely, we remove two types of accounts that are not useful to our purposes: 1) accounts outside Spanish territory, and 2) accounts where locations cannot be guessed, either because the field is empty, or because the provided location is not accurate or does not exist. After cleaning the data, we have a remaining sample of 90,132 accounts.

\subsection{Extracting Occupational Categories From Twitter User Biographies}

We rely on the Twitter users' public profiles information to identify their occupations. Specifically, we extract information from user' biographies, self-introductions written in free form where users (often) explicitly state their occupation. We elaborate a dictionary of occupations based on the National Classification of Occupations (CNO). However, we must execute different Natural Language Processing techniques to deal with two major problems. First, the titles of the occupations and biographies are not normalized, so we perform a lemmatization process to extract the root of all the words in the sentences. We do this by using a FreeLing tool (Padró, 2012), which also allows us to set Part of Speech (PoS) tags to every word in the texts, identifying irrelevant words such as prepositions, conjunctions, articles, or intransitive verbs. Once we have removed these words, the remaining lemmas in the CNO dataset are considered, and a Bag of Words (Maas et al., 2011) technique is used to represent every individual occupation; that is, every occupation is represented by a numeric vector where every element counts the number of times a lemma appears in the CNO title. Finally, we also represent the biographies as a vector of lemma appearances, and we assign every biography to the nearest $\mathrm{CNO}$ in terms of cosine distance. In one further step, we classify every occupation in one of the following groups ${ }^{5-6}$ :

1. TEM occupations (technology, engineering, and mathematics): This group includes computer occupations, software developers, data scientists, etc.

2. Professional occupations (except TEM): This group encompass occupations from the life, physical, and social sciences, as well as other professions such as lawyers, architects, etc.

After applying this methodology, we have not been able to classify some users in one of these two groups, either because of their insufficient biography length or because they are not using any keyword in our dictionary. These users have been discarded for the rest of the analysis. Once this process is performed, we have a final sample of 20,701 accounts, distributed between 7,130 users in TEM occupations and 13,571 professionals from other sectors. This sample is validated in several ways to ensure that it has the appropriate characteristics for our purposes. Specifically, we check on the size and composition of the sample, geospatial distribution, and Twitter activity levels. Results corroborate that the groups are suitable to launch the experiment. Detailed information about the validation process is presented in the "Data Validation" section later in this paper.

\subsection{Data Collection}

After classifying users by occupational category, we proceed to identify the influencers of each group. Essentially, influencers are those personalities in political or public life who have the power to shape the opinions of an audience, mostly thanks to their social media following. In non-reciprocal social networks such as Twitter, being a follower of another account means the user is willing to read the content that account holder shares, as well as his or her opinions or any other piece of information revealed. In other social data sources, such as Call Detail Records from telecommunication companies (Wang, 2011) or viral marketing campaigns (De Bruyn, 2008), it is possible to build a more complete social network; then, using social network analysis metrics, such as betweenness centrality (Freeman, 1977), or performing datadriven simulations on the network (Kitsak, 2010), we could assign values to the importance and influence of the participants. However, it is not possible to extract the full online social network through publicly available Twitter APIs because of the API request rate limitations, so we choose a different approach. To detect influencers, we examine which

\footnotetext{
${ }^{4} \mathrm{http} / / /$ www.ine.es/dyngs/INEbase/en/operacion.htm?c=Estadistica_C\&cid=1254736177033\&menu=ultiDatos\&idp=125473597661

${ }^{5}$ We initially considered including a third occupational group: low-skilled workers, which included both service and bluecollar occupations. However, in line with prior research, we find this group to be heavily underrepresented. Some scholars point out that low-skilled jobs are less likely to participate on Twitter (Sloan et al., 2015). Also, they may be less likely to state their occupations on the platform. Taking these reasons into account, we limit the study to professionals of all other sectors.

${ }^{6}$ For complete information about the skills, knowledge, and abilities required in the occupations, see https://www.onetonline.org.
} 
accounts have the highest numbers of followers in our groups. First, we obtain a collection of user objects for every user whom the users in our sample are following (also known as their "friends"). Next, we order the list by frequency of appearance and identify the most popular accounts within the two groups - namely, those followed by at least 75 percent of the group. Finally, we collect full information on the selected accounts and examine them ${ }^{7}$. With this methodology, we are building the ego-network of the users in the experiment and then computing the degree (number of total connections) for all the users in the resulting graph (Leskovec, 2012).

In both groups, the most popular accounts are of general interest (e.g., newspapers, etc.) that do not allow us to discriminate among groups. Leaving these accounts aside, we clearly detect two influencers. Within the group of TEM workers, we identify an outstanding national business adviser. For more than twenty years, this personality has worked with organizations and professionals, focusing on manager development, employee motivation, professional reinvention, and the search for new professional opportunities. As for the second group, we identify a national publicist, music producer, songwriter and TV personality. Currently, he is very well known as a judge on popular television talent shows. Both personalities have a long-term professional relationship, having debated several times on TV shows and social media. Interestingly, the TEM influencer does not appear among the top favorites of the non-TEM group, nor does the non-TEM influencer appear among the top favorites of the TEM group. This suggests that our target groups have starkly different interests and exhibit their own idiosyncrasies.

\subsection{Analytical Strategy}

To evaluate differences in behavior between groups vis-à-vis online ads, we carry out a split test (also known as multivariate testing, or A/B test), which involves conducting a controlled randomized online experiment. Specifically, we aim to measure a user's attention to online recruitment ads using campaign metrics such as impressions, engagement, and clicks. With this goal in mind, we designed a completely new recruitment brand. This yields important advantages, for example eliminating bias by guaranteeing that no group has any positive or negative perceptions of a given brand. During the months leading up to the experiment, a Twitter account was created, began to follow random users, and retweeted Human Resources Analytics general information, all to imitate a real brand account and to simulate some activity.

The experiment consists of launching an online recruitment call using three alternative ads. Ads consist of text (call for talent) and a picture. The text is group-tailored, meaning it makes explicit reference to target members of groups. It is important to note that for each group, we use the same text across ads, varying the pictures as follows:

Ad 1: Brand. The first ad focus on brand. In this ad, as shown below, the logo appears centered in the image, and the call for talent appears over the box.

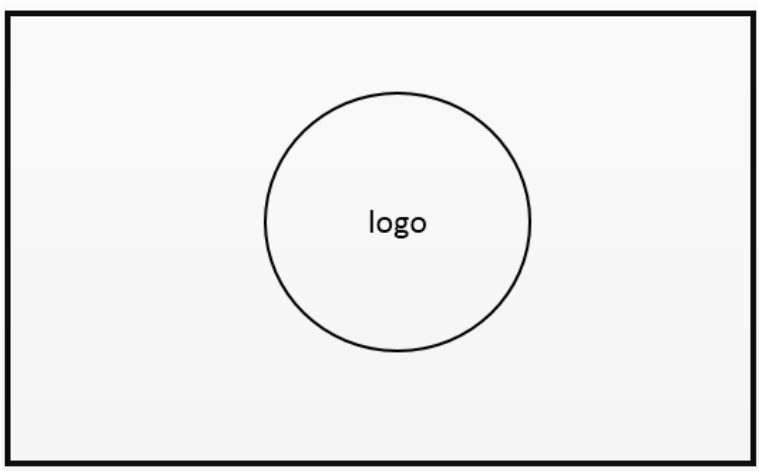

Figure 1. Ad 1: Brand Call for talent

\footnotetext{
${ }^{7}$ To this aim, we call the GET friends/list endpoint and the GET users/lookup endpoint.
} 
Ad 2: Message. The second ad reduces brand prominence in favor of the message. Here, the call appears both over the box and in a central location within the picture. The ad also includes a neutral quote, "We are waiting for you":

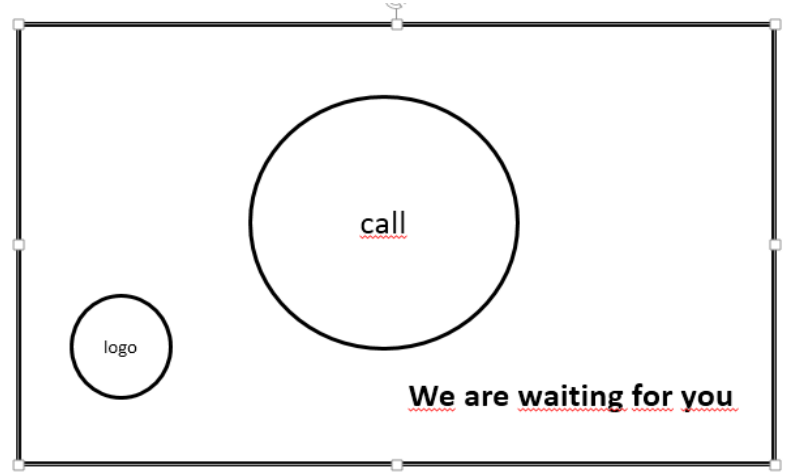

Figure 2. Ad 2: Message Call for talent

Ad 3: Motivated. The third ad is identical to the second except for the quote. In this case, we substitute the neutral quote for an inspirational quote from the group influencer. This is expected to increase both credibility and motivation (Allen et al., 2004; Allen et al., 2007).

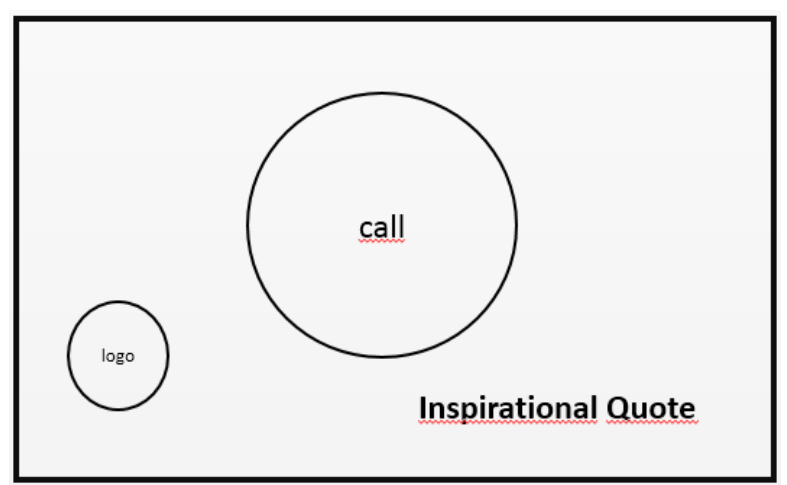

Figure 3. Ad 3: Motivated Call for talent

When running the experiment, incoming traffic is distributed among the three variations, with none of the participants knowing that they are part of an experiment. ${ }^{8}$ More specifically, we segment the original groups into three samples of similar size in the following manner:

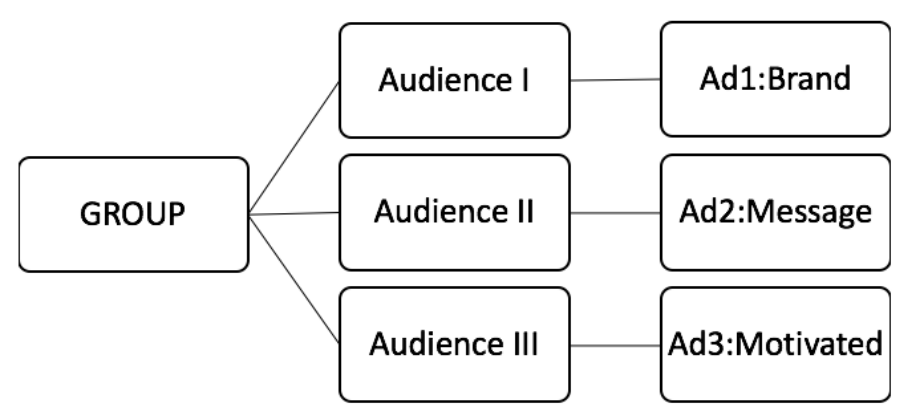

Figure 4. Segmentation

To sum up, there are six ads (three per group). We expect statistically significant differences in behavior to emerge, both among groups and among the different ads. The results from each variation are compared to determine which version is the most effective.

\footnotetext{
${ }^{8}$ In a later step, participants are provided with information about the experiment. All information remains confidential and cannot be associated with names. If for any reason individuals decide not to participate, we eliminate their data. No such petitions have been registered.
} 


\subsection{Launching the Campaigns: Metrics}

We launch our campaigns through Twitter ads. To do so, we provide Twitter the identification numbers of users in each of the six audiences, together with their corresponding ads. ${ }^{9}$ Campaigns are launched to controlled targets such that individuals in any audience will see only the advertisement corresponding to their group.

The six ads are launched simultaneously, starting January 18, 2017, and keep active — that is, repeatedly shown — daily from 7:00 a.m. to 11:00 p.m. until it reaches every member of the audience. The following chart shows the impression rate (defined below) of all campaigns concurrently. Between January 21 and January 22, the campaigns paused for the weekend.

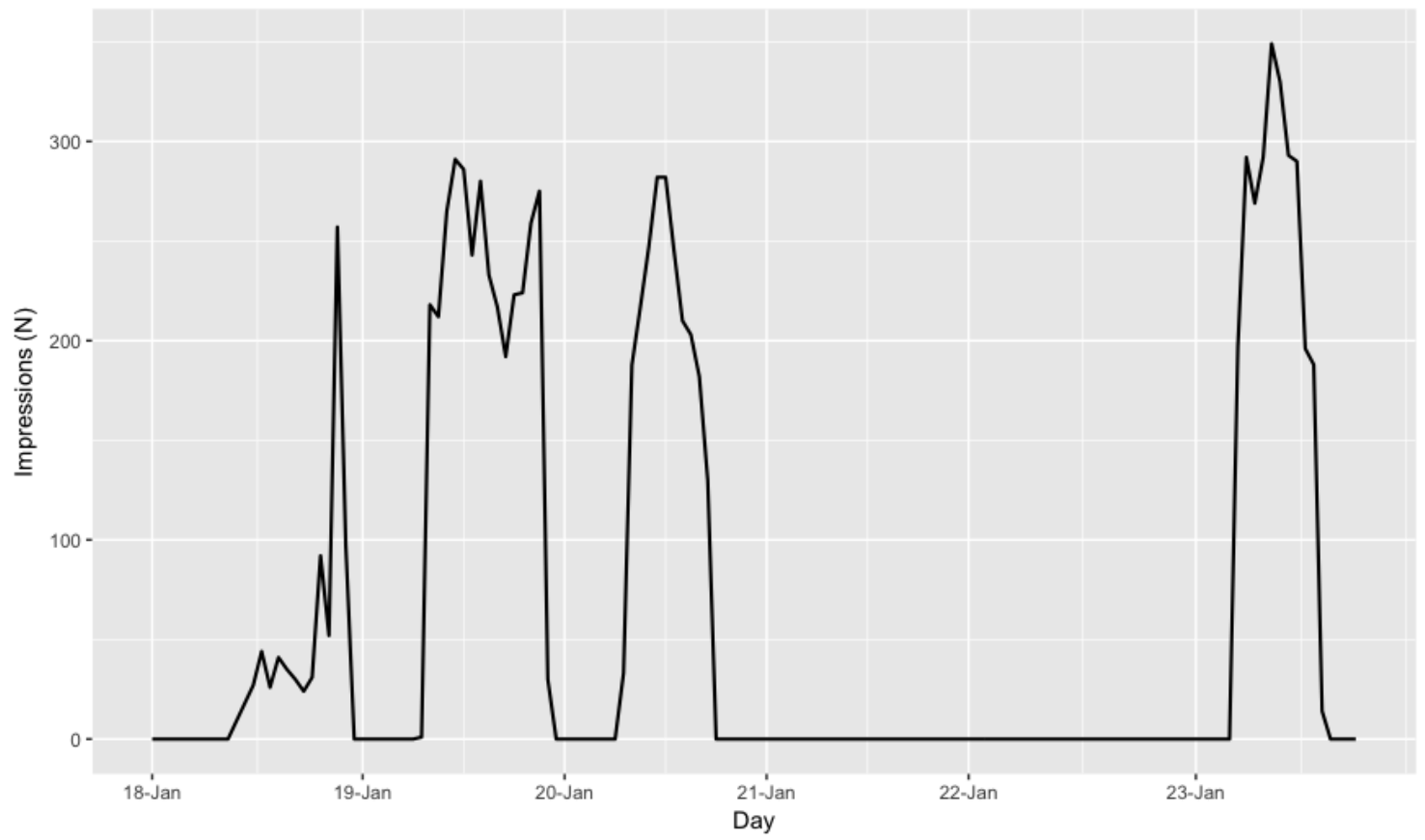

Figure 5. Number of impressions by day/hour

There are three measures generated in the ad process:

- Impressions: the number of times the $a d$ is shown

- Number of clicks: total number of clicks the ad receives

- Number of interactions: total number of times that users interact with the ad (retweets, likes, etc.)

Using the three measures, we create two indicators: first, the click through rate (CTR) measures the number of clicks on the ad divided by the number of times the ad has been shown, expressed as a percentage; second, the engagement rate (ER), measured as the number of interactions divided by the total number of impressions.

(1) $C T R=\frac{\text { Total of Clicks }}{\text { Total of impressions }}$

(2) $\mathrm{ER}=\frac{\text { Total of interactions }}{\text { Total of impressions }}$

The relevance of each indicator varies depending on a given campaign's objective. The engagement rate (ER) is especially crucial when the ultimate goal is content dissemination through social media. On other occasions, brands want to make the website-rather than social media platforms-the ultimate destination to display certain content, make sales, or simply increase their traffic. In these cases, the CTR is more important.

${ }^{9}$ Twitter validates the IDs and deletes those considered inactive (for example, those who have not logged in recently). This guarantees that all users are regularly active on Twitter and will see the campaign. 


\section{Results}

In the following section, we analyze campaign metrics (CTR and ER) based on occupation type. First, we compare the participation rates by occupational groups. Then, we split the results by ad type to examine within-group differences.

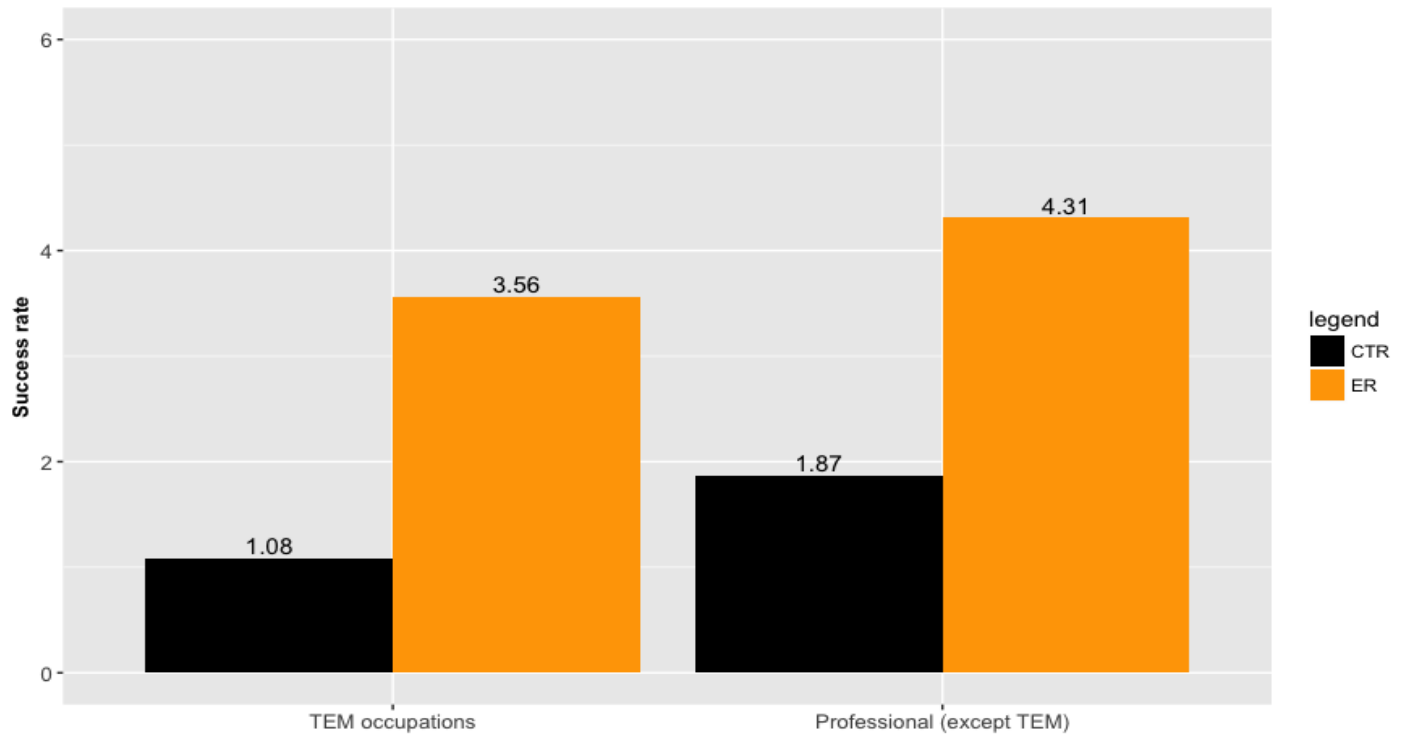

Figure 6. Click trough rate and engagement rate by occupational groups.

\begin{tabular}{lcc} 
PROPORTION TEST & CTF & ER \\
\hline STEM-non STEM & $* *$ & $* * *$ \\
\hline \hline$* \mathrm{p}<0.05 * * * \mathrm{p}<0.001$ &
\end{tabular}

Figure 6 shows the participation rate for every group member in the experiment, without differentiating by ad type. The black columns represent the click through rate (CTR) metric, and the orange ones the engagement rate (ER) metric. The graph displays lower rates of participation among workers from the TEM sectors. They are less likely to click on the job ad and to interact with it. The proportion test below Figure 6 indicates that the observed differences between the two groups are statistically significant for both CTR and ER. As predicted in H1, workers in high demand are less prone to react to campaigns than workers in other occupations.

Once we split the results by ad type, significant differences emerge within the TEM categories. As observed in Figure 7, TEM's propensity to click on our link increases significantly when the ad is tailored. To be precise, the CTR varies from 0.61 in the message ad, to 0.72 in the brand ad, to 1.9 in the motivated ad. Similarly, the ER metric increases from 2.0 in the message ad to 5.5 in the motivated ad. Here again, proportion tests corroborate that differences are statistically significant both for CTR and ER.

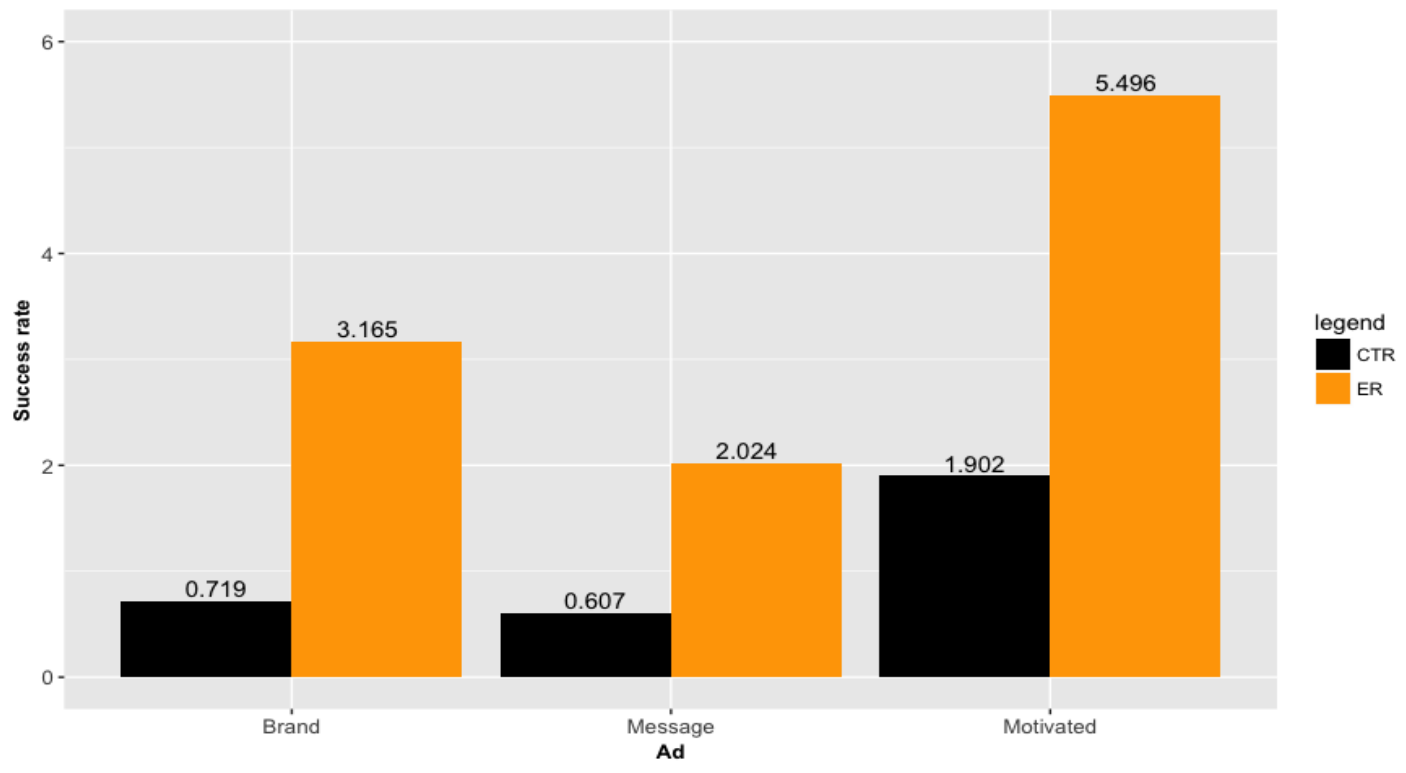


Figure 7. Participation rates by ad type-TEM occupations

\begin{tabular}{lcc} 
PROPORTION TEST & CTF & ER \\
\hline Brand-Message & n.s. & n.s. \\
Brand-Motivated & $* * *$ & $* * *$ \\
Message-Motivated & $* * *$ & $* * *$ \\
\hline \hline$* * \mathrm{p}<0.05 * * * \mathrm{p}<0.001$ & &
\end{tabular}

A different scenario is observed among professionals from other sectors. A brief glance at Figure 8 reveals that all three of the ads register similarly. This indicates that the probability of participation among workers in non-TEM occupations does not vary with the type of ad. Indeed, CTR varies from 1.5 in the message ad to 2.0 in the motivated ad to 2.1 in the brand ad. With regard to ER, values range from 4.0 to 4.8. Results from the proportion test confirm that the observed differences are not statistically significant, and these workers do not discriminate among brand, message, and motivated ads.

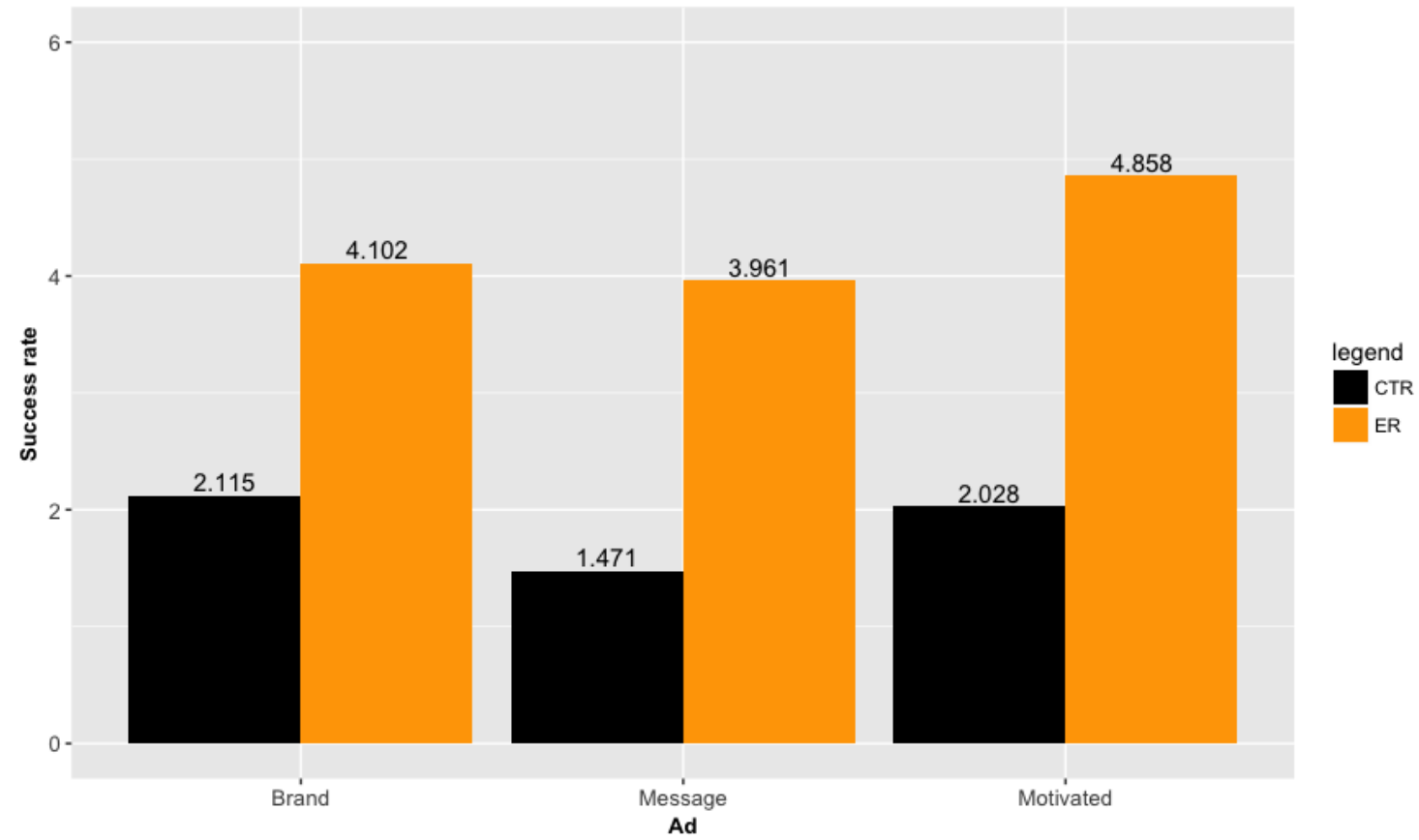

Figure 8. Participation rates by ad type-Professional occupations (except TEM)

\begin{tabular}{lll} 
PROPORTION TEST & CTF & ER \\
\hline Brand-Message & n.s. & n.s. \\
Brand-Motivated & n.s. & n.s. \\
Message-Motivated & n.s. & n.s. \\
\hline$*_{* *}<0.05 * * * p<0.001$ & &
\end{tabular}

Providing a general overview, Figure 9 displays the difference between motivated and brand ads, comparing the results by occupational category. Dark colors indicate bigger differences between the two types of ads, and light colors denote smaller differences. As predicted in H2, motivated ads increase the CTR 1.2 percent among TEM workers, while no gain is observed for the rest of professional occupations. In the case of ER, we observe a moderate (non-significant) gain of about 0.8 percent among professional occupations, in comparison with the 2.5 percent gain among workers in TEM occupations. All in all, findings confirm that user propensity to participate in online campaigns interacts with occupational category. We found that workers in high demand are significantly less likely to participate in the campaigns than other workers. Nevertheless, they are particularly sensitive to motivated ads, which is not the case for the rest of the workers. Consequently, incurring the cost of customization is only worthwhile when seeking to recruit workers in technologyrelated industries. 


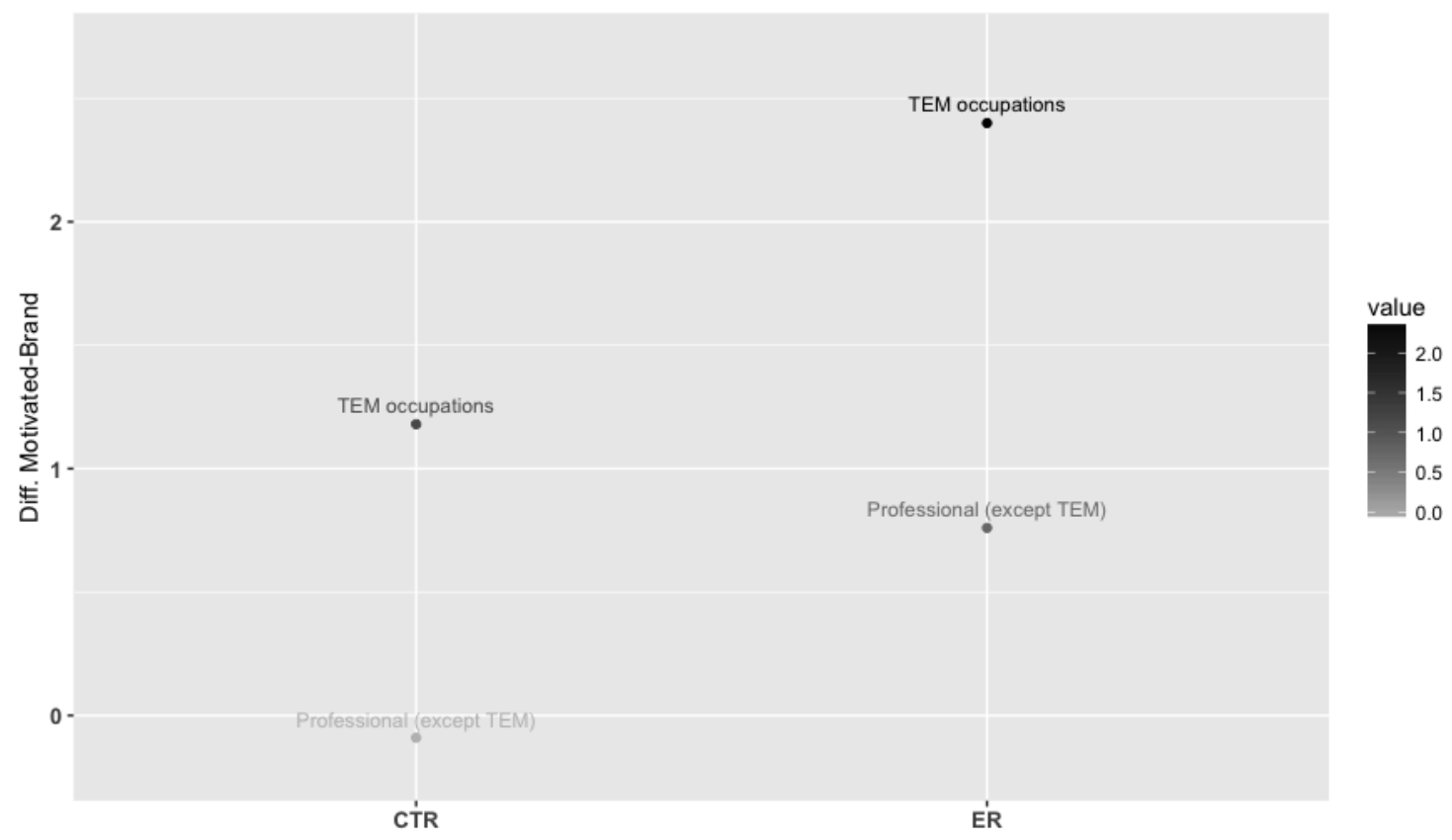

Figure 9. Difference between Brand and Motivated ad by occupational group

\section{Data Quality and Validation Checks}

In this section, we seek to ensure that differences revealed in our experiment are robust and not merely explained by data characteristics. We accomplish this by validating data in three different ways: comparison with national statistics, Twitter activity levels, and geographical distribution.

\subsection{Comparison with National Statistics}

The first step in validating our data is to contrast the Twitter sample with data from the Labor Force Survey (LFS) 2016. The LFS is carried out by the National Institute of Statistics on a quarterly basis. It represents the largest collection of national information on employment status of individuals living in the Spanish territory. What makes this data preferable to data from other sources is that the LFS does not discriminate either by worker origin or by type of contract. In other words, the LFS interviews all individuals regardless of their legal status in the country and their work status. For this reason, it is an ideal dataset to contrast with the occupational and geographical information obtained through Twitter.

Table 1 displays the distribution of workers in both LFS and Twitter. As observed, the distribution of workers by occupational category is very similar in the two samples, suggesting that our data are suitable for analyses.

Table 1. Sample composition: LFS vs. Twitter data

\begin{tabular}{ccccc}
\hline & \multicolumn{2}{c}{ EPA } & \multicolumn{2}{c}{ Twitter } \\
\cline { 2 - 5 } & $\mathrm{N}$ & $\%$ & $\mathrm{~N}$ & $\%$ \\
\hline TEM occupation & 6420 & 31.25 & 7130 & 34.44 \\
Professional occup (except TEM) & 14188 & 68.85 & 13571 & 65,56 \\
\hline
\end{tabular}

\subsection{Twitter Activity Levels}

For our test to be efficient, target groups must maintain similar rhythms of Twitter activity. This is crucial to ensure that the success (or failure) of our campaigns responds to the idiosyncrasies of the individuals in different occupations-and not to variations in their levels of network activity. Here, we compare four metrics of web activity: Status and Favorites (as a proxy of activity level) and Friends and Followers (as a proxy of connectivity level). Figure 10 displays the distribution for the four indicators. The grey line corresponds to workers in TEM occupations, and the black line to other workers. As clearly observed in the four plots, the distribution of the two groups significantly overlap, and noteworthy differences are not perceived among groups. 

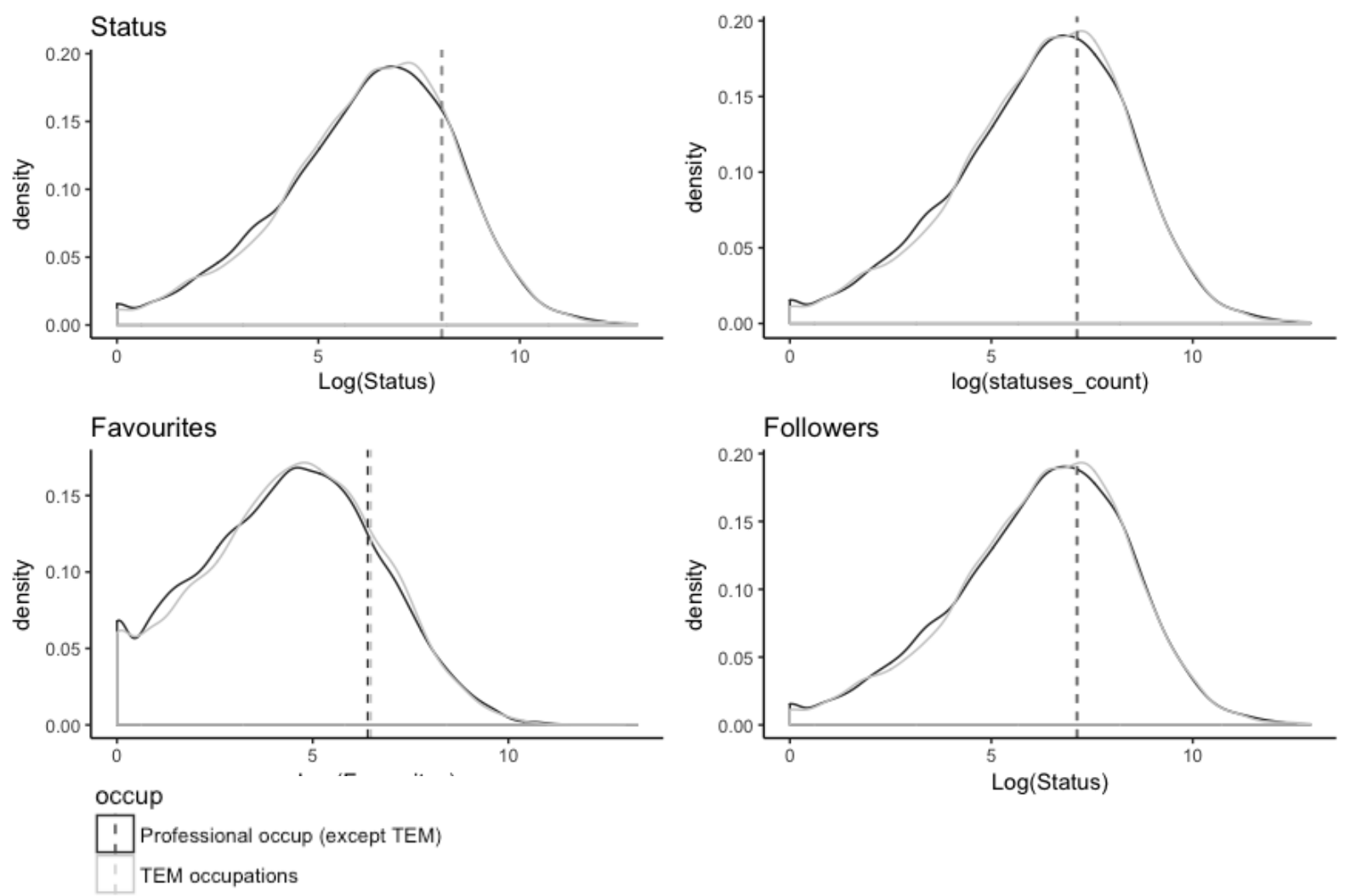

Figure 10. Distribution of Twitter indicators of activity level

\subsection{Geographical Distribution}

For the purposes of this study, it is desirable that target groups are represented all over the Spanish territory to make sure that our results are not affected by urban/rural bias or other distributional characteristics. User location coordinates are obtained through the Google Maps API. It is important to note that since locations are free text, the Google Maps API returns coordinates by approximation. Generally speaking, this means that users across, say, Madrid, would all return the same coordinates. The maps below show that users in the two occupational categories are consistently represented across the territory, making data suitable for the experiment. (An interactive map can be seen here:

https://mtorre.shinyapps.io/app_occup_distribution/)

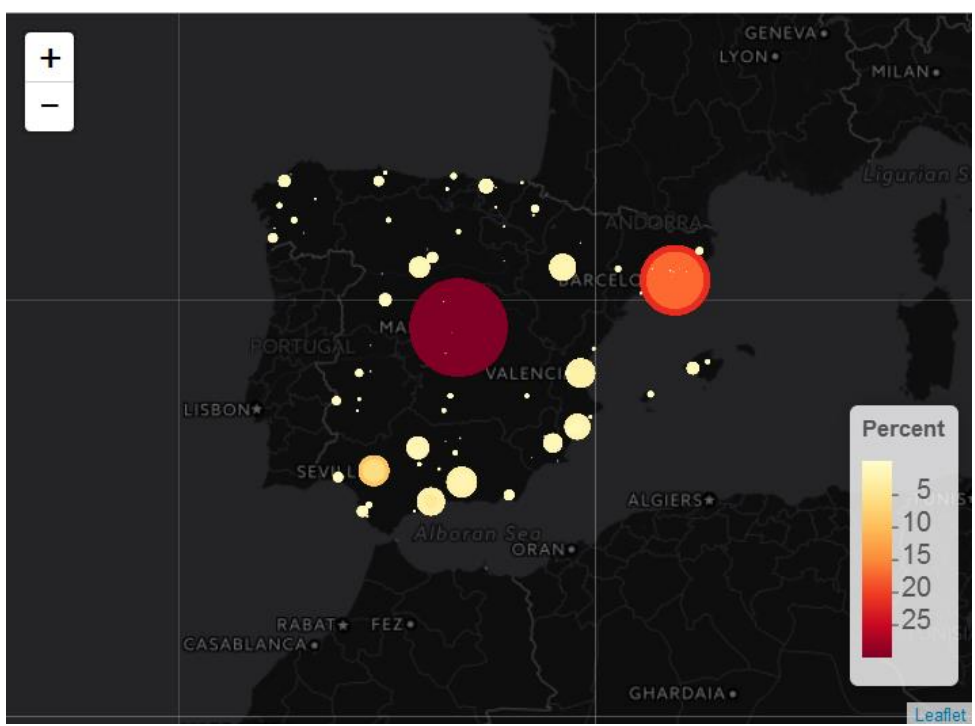




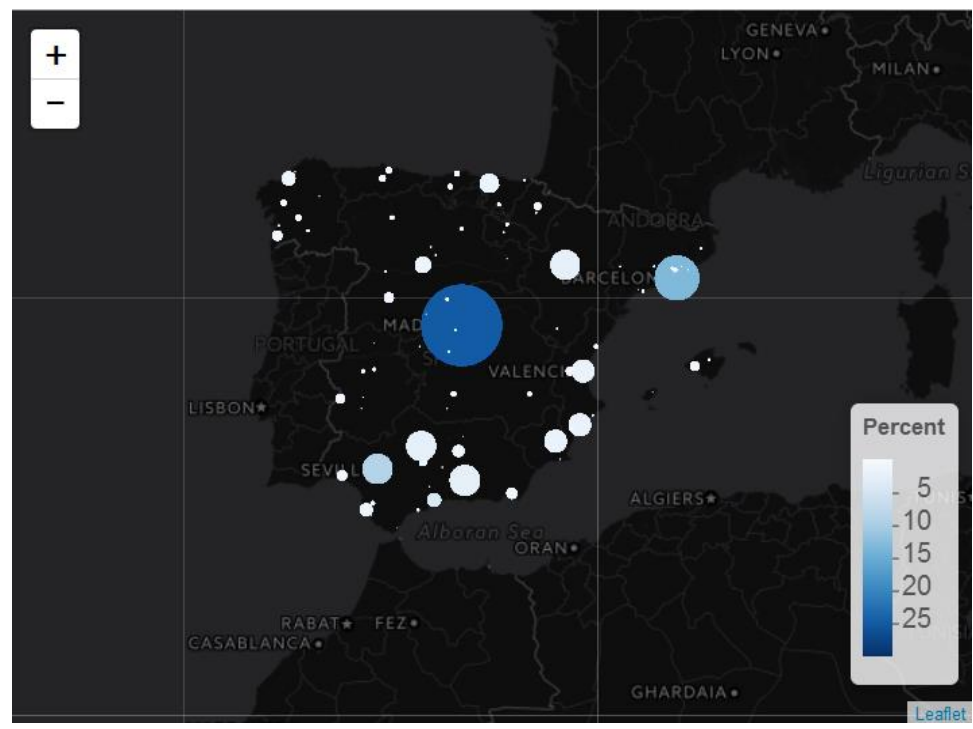

Figure 11. Territorial distribution of the sample: TEM workers (top) and Professionals from other sectors (bottom)

\section{Conclusions}

The emergence of the Internet and social media networks have massively changed how companies attract workers. Despite increasing research on recruitment methods and technologies, scholars have largely ignored how Internet recruitment success varies across types of workers. This paper aims to fill this gap in the online recruitment literature by examining to what extent pre-hiring outcomes vary according to position in the labor market.

Nowadays, technology is a battleground for talent, with about 40 percent of companies planning to expand their workforce. Scholars are thus right to talk about a second war for talent underway. Here, we contend that the increasing demand for technology-related industry profiles might be causing fatigue among workers, who often receive offers for which they are overqualified or do not suit them. Taking this into consideration, we hypothesized that workers in high-demand occupations (TEM) are less responsive to online recruitment attempts, and therefore extra efforts (motivation) are required to catch their attention.

This study uses Twitter data to test these hypotheses. Employing an experimental methodology, we examine how people in TEM occupations and other non-TEM sectors react to online brand, message and motivated job-procurement ads. Comparing campaign metrics - namely, click through rate and engagement rate-we found that, as anticipated, both CTR and ER are lower among TEM workers than among professionals from other sectors. However, the benefits of motivated ads (as compared to those focusing on brand or message) are particularly large among TEM workers. As expected, results show that workers in high demand are harder to persuade, but that it is worth incurring the cost of procuring personal information to increase a posting's credibility. Workers from other sectors, however, do not discriminate between the various ad types, and therefore investing in customization does not pay off.

Overall, this study has important implications for organizational effectiveness. First, the findings reveal that pre-hiring outcomes vary according to the type of target. The increasing differentiation among workers in TEM and non-TEM occupations should be of interest to organizations competing for scarce human resources. Also, the results underscore the relevance of social networks in the online recruitment process, allowing recruiters both to contact people from all over the world and to extract useful information for approaching them. Furthermore, by selecting the target audience in advance, our methodology also contributes to reduce undesired side effects of web recruitment, as for example generate too many applications from unqualified applicants (Dineen et al., 2007; Sonnet et al., 2005). The experiment in this study focuses on the Spanish territory, but conclusions are easily extrapolated everywhere the second war for talent is taking place. Inevitably, this study also raises a number of interesting questions that cannot be answered with the available data. Future research is needed to control for brand awareness, analyzing the effect of motivated ads for small, medium, and large companies when the user has heard of the recruiter. Also, it would be relevant to consider whether observed differences by occupation also emerge in political campaigns, e-commerce, and other online outreach efforts. 


\section{References}

Allen, D. G., Mahto, R. V., \& Otondo, R. F. (2007). Web-based recruitment: Effects of information, organizational brand, and attitudes toward a web site on applicant attraction. Journal of Applied Psychology, 92, 1696-1708. https://doi.org/10.1037/0021-9010.92.6.1696

Allen, D. G., Van Scotter, J. R., \& Otondo, R. F. (2004). Recruitment communication media. Impact on pre-hire outcomes. Personnel Psychology, 57, 143-17. https://doi.org/10.1111/j.1744-6570.2004.tb02487.x

Baum, M., \& Kabst, R. (2014). The Effectiveness of Recruitment Advertisements and Recruitment Websites: Indirect and Interactive Effects on Applicant Attraction. Human Resource Management, 53(3), 353-378. https://doi.org/10.1002/hrm.21571

Beechler, S., \& Woodward, I. C. (2009). The Global War for Talent. Journal of International Management, 15, $273-285$. https://doi.org/10.1016/j.intman.2009.01.002

Boswell, W. R., Roehling, M. V., LePine, M. A., \& Moynihan, L. M. (2003). Individual job-choice decisions and the impact of job attributes and recruitment practices: A longitudinal field study. Human Resource Management, 42, 2337. https://doi.org/10.1002/hrm.10062

Boyd, D., \& Marwick, A. E. (2011). Social Privacy in Networked Publics: Teens Attitudes, Practices, and Strategies. pp. 1-29. In: Proceedings of the A decade in Internet Time: Symposium on the Dynamics of the Internet and Society, 21 - 24 September 2011, University of Oxford.

Braddy, P. W., Thompson, L. F., Wuensch, K. L., \& Grossnickle, W. F. (2003). Internet Recruiting. The Effects of Web Page Design Features. Social Sciences Computer Review, 21(3), 374-385. https://doi.org/10.1177/0894439303253987

Breaugh, J. A. (2008). Employee recruitment: Current knowledge and important areas for future research. Human Resource Management Review, 18, 103-118. https://doi.org/10.1016/j.hrmr.2008.07.003

Caers, R., \& Castelyns, V. (2011). LinkedIn and Facebook in Belgium: The Influences and Biases of Social Network Sites in Recruitment and Selection Procedures. Social Sciences Computer Review, 29(4), 437-448. https://doi.org/10.1177/0894439310386567

Capelli, P. (2008). Talent on Demand: Managing Talent in an Age of Uncertainty. Boston, MA: Harvard University Press. Cappelli, P. (2001). Making the Most of On-Line Recruiting. Harvard Business Review, 139-146.

Chapman, D. S., \& Webster, J. (2003). The Use of Technologies in the Recruiting, Screening, and Selection Processes for Job Candidates. International Journal of Selection and Assessment, 11(2/3), 113-120. https://doi.org/10.1111/1468-2389.00234

De Bruyn, A., \& Lilien, G. L. (2008). A multi-stage model of word-of-mouth influence through viral marketing. International Journal of Research in Marketing, 25(3), 151-163. https://doi.org/10.1016/j.ijresmar.2008.03.004

Dineen, B. R., Ash, S. R., \& Noe, R. A. (2002). A web of applicant attraction: Person-organization fit in the context of Web-based recruitment. Journal of Applied Psychology, 87, 723-734. https://doi.org/10.1037/0021-9010.87.4.723

Dineen, B. R., Ling, J., Ash, S. R., \& DelVecchio, D. (2007). Aesthetic properties and message customization: Navigating the dark side of web recruitment. Journal of Applied Psychology, 92, 356-372. https://doi.org/10.1037/0021-9010.92.2.356

Ding, Y., \& Jiang, J. (2014). Extracting Interest Tags from Twitter User Biographies. Information Retrieval Technology. 268-279.

Dinnen, B. R., Ling, J., Ash, S. R., \& Devon D. (2007). Aesthetic Properties and Message Customization: Navigating the Dark Side of Web Recruitment. Journal of Applied Psychology, 92(2), 356-372.

Freeman, L. C. (1977). A set of measures of centrality based on betweenness. Sociometry, 35-41. https://doi.org/10.2307/3033543

Friestad, M., \& Wright, P. (1994). The persuasion knowledge model: How people cope with persuasion attempts. Journal of Consumer Research, 21-31. https://doi.org/10.1086/209380

Gardner, T. M. (2002). In the Trenches at the Talent Wars: Competitive Interaction for Scare Human Resources. Human Resource Management, 41(2), 225-237. https://doi.org/10.1002/hrm.10033

HR Barometer. (2015). Putting People First. How HR is at the Forefront of Business Growth and Transformation. Michael 
Page.

Humpreys, L., Gill, P., \& Krishnamurthy, B. (2014). Twitter: A Content Analysis of Personal Information. Information, Communication and Society, 17(7), 843-857. https://doi.org/10.1080/1369118X.2013.848917

Interactive Advertising Bureau https://www.iab.com/ .

Jurdak, R., Zhao, K., Liu, J., AbouJaoude, M., Cameron, M., \& Newth, D. (2015). Understanding human mobility from Twitter. PloS one, 10(7), e0131469. https://doi.org/10.1371/journal.pone.0131469

Jurgens, D., Finnethy, T., McCorriston, J., Tian Xu, Y., \& Ruths, D. (2015). Geolocation Prediction in Twitter Using Social Networks: A Critical Analysis and Review of Current Practice. Association for the Advancement of Artificial Intelligence (www.aaai.org).

Kay, A. S. (2000). Recruiters embrace the Internet. Information Week, 778, 72-80

Kim, N. Y., \& Sundar, S. S. (2012). Personal Relevance versus Contextual Relevance: The Role of Relevant Ads in Personalized Websites. Journal of Media Psychology: Theories, Methods, and Applications, 24(3), 89-101. https://doi.org/10.1027/1864-1105/a000067

Kitsak, M., Gallos, L. K., Havlin, S., Liljeros, F., Muchnik, L., Stanley, H. E., \& Makse, H. A. (2010). Identification of influential spreaders in complex networks. Nature physics, 6(11), 888-893.

Kivran-Swaine, F., Govindan, P., \& Naaman, M. (2011). The impact of network structure on breaking ties in online social networks: unfollowing on twitter. In Proceedings of the SIGCHI conference on human factors in computing systems (pp. 1101-1104). ACM.

Leetaru, K. H., Wang, S., Cao, G., Padmanabhan, A., \& Shook, E. (2013). "Mapping the global Twitter hearbeat: The geography of Twitter". First Monday, 18(5).

Leskovec, J., \& Mcauley, J. J. (2012). Learning to discover social circles in ego networks. In Advances in neural information processing systems (pp. 539-547).

Li, L., Goodchild, M. F., \& Xu, B. (2013). Spatial, temporal, and socioeconomic patterns in the use of Twitter and Flickr. Cartography and geographic information science, 40(2), 61-77. https://doi.org/10.1080/15230406.2013.777139

Llorente, A., Garcia-Herranz, M., Cebrian, M., \& Moro, E. (2015). Social media fingerprints of unemployment. PloS one, 10(5), e0128692. https://doi.org/10.1371/journal.pone.0128692

Maas, A. L., Daly, R. E., Pham, P. T., Huang, D., Ng, A. Y., \& Potts, C. (2011). Learning word vectors for sentiment analysis. In Proceedings of the 49th Annual Meeting of the Association for Computational Linguistics: Human Language Technologies-Volume 1 (pp. 142-150). Association for Computational Linguistics.

Mandhanya, Y., \& Shah, M. (2010). Employer Branding-A Tool for Talent Management. Global Management Review,4(2) 43-48

Maslowska, E. H. (2013). "Just for You! A Study into the Effectiveness and the Mechanism of Customized Communication. http://hdl.handle.net/11245/1.395584

McDonald, P., Thompson, P., \& O’Connor, P. (2016). Profiling employees online: shifting public-private boundaries in organizational life. Human Resource Management Journal, 26(4), 541-556.

https://doi.org/10.1111/1748-8583.12121

Michaels, E., Handfield-Jones, H., \& Axelrold, B. (2001). The War for Talent. Boston, MA: Harvard Business School Press.

Morris, B. (2013). More consumers prefer online shopping. Wall Street Journal. https://www.wsj.com/articles/SB10001424127887324063304578523112193480212

Padró, L., \& Stanilovsky, E. (2012). Freeling 3.0: Towards wider multilinguality. In LREC2012.

Shatz, I. (2017). Fast, Free, and Targeted: Reddit as a Source for Recruiting Participants Online. Social Science Computer Review, 35(4), 537-549. https://doi.org/10.1177/0894439316650163

Sloan, L., Morgan. J., Burnap, P., \& Williams. M. (2015). Who Tweets? Deriving the Demographic Characteristics of Age, Occupation and Social Class from Twitter Users Meta-Data. PLoS One, 10(3), e0115545. https://doi.org/10.1371/journal.pone.0115545

Spector, P. E. (2000). Selecting employees. In P. E. Spector (Ed), Industrial and organizational psychology: Research and practice, 125-151. New York: John Wiley.

Stone, D. L., Lukaszewski, K., \& Isenhour, L. C. (2005). E-Recruiting: Online Strategies for Attracting Talent. In H. 
Gueutal and D.L. Stone (eds.), The Brave New World of EHR: Human Resources in the Digital Age ,22-53. New York: John Wiley and Sons

The war for talent. McKinsey and Company. (1997).

Van Doorn, J., \& Hoekstra, J. C. (2013). Customization of online advertising: The role of intrusiveness. Marketing Letters, 24(4), 339-351. https://doi.org/10.1007/s11002-012-9222-1

Vorhauser-Smith, S. (2013). Three Companies Nailing Social and Mobile for H.R. Forbes. https://www.forbes.com/sites/sylviavorhausersmith/2013/07/09/three-companies-nailing-social-mobile-for$\mathrm{hr} / \# 6$ eaae5c28925

Walrave, M., Poels, K., Antheunis, M. L., Van den Broeck, E., \& Van Noort, G. (2016). Like or dislike? Adolescent's responses to personalized social network site advertising. Information, Communication and Society, 1-18

Wang, D., Pedreschi, D., Song, C., Giannotti, F., \& Barabasi, A. L. (2011). Human mobility, social ties, and link prediction. In Proceedings of the 17th ACM SIGKDD international conference on Knowledge discovery and data mining (pp. 1100-1108). ACM. https://doi.org/10.1145/2020408.2020581

Xu, D. J., Liao, S. S., \& Li, Q. (2008). Combining Empirical Experimentation and Modeling Techniques: A Design Research Approach for Personalized Mobile Advertising Application. Decision Support Systems, 44(3), 710-724. https://doi.org/10.1016/j.dss.2007.10.002

Yang, J., \& Leskovec, J. (2011). Patterns of temporal variation in online media. In Proceedings of the fourth ACM international conference on Web search and data mining (pp. 177-186). ACM.

Zusman, R. R., \& Landis, R. S. (2002). Applicant preferences for web-based versus traditional job postings. Computers in Human Behavior, 18, 285-296. https://doi.org/10.1016/S0747-5632(01)00046-2

\section{Copyrights}

Copyright for this article is retained by the author(s), with first publication rights granted to the journal.

This is an open-access article distributed under the terms and conditions of the Creative Commons Attribution license which permits unrestricted use, distribution, and reproduction in any medium, provided the original work is properly cited. 